\title{
3 Research Soure \\ The yield of routine histopathology in fistula-in-ano: a retrospective analysis
}

\author{
Umesh Jayarajah \\ University of Colombo Faculty of Medicine \\ Isuru S Almeida \\ Faculty of Medicine, University of Colombo \\ Dharmabandhu Nandadeva Samarasekera ( $\nabla$ samarasekera58@yahoo.co.uk) \\ University of Colombo https://orcid.org/0000-0003-2229-7549
}

\section{Research note}

Keywords: fistula-in-ano, histopathology, Tuberculosis, Crohn's disease

Posted Date: April 23rd, 2020

DOI: https://doi.org/10.21203/rs.3.rs-22407/v1

License: (c) (i) This work is licensed under a Creative Commons Attribution 4.0 International License. Read Full License 


\section{Abstract \\ Objective}

Fistulae-in-ano with a specific aetiology such as TB and Crohn's are usually complex and challenging to treat. This study was aimed to determine the yield of routine histological analysis in fistula-in-ano, in detecting specific aetiology. Histopathology reports of all patients without a previous diagnosis, who underwent surgery for fistulae-in-ano were retrospectively analysed.

\section{Results}

A total of 215 patients [median age:40 years(range:14-73), males $=178(82.8 \%)$ ] were analysed. The majority $(75 \%, n=161)$ were simple fistulae and recurrent $(67 \%, n=145)$. Histological evaluation revealed inflamed granulation tissue in $94.9 \%(n=204)$ of patients. Five $(2.3 \%)$ patients had conclusive evidence of Crohn's disease and three $(1.4 \%)$ had tuberculosis. One patient $(0.5 \%)$ had evidence of adenocarcinoma with mucinous differentiation. Significant proportion of fistula with a specific aetiology were complex fistulae $(82 \%$ vs. $22 \%, p<0.001)$ and associated with abscess/collections $(45.5 \%$ vs. $11.8 \%, p<0.001)$. Age, type of fistula, level of internal opening, recurrence and presence of haemorrhoids were comparable in those with and without a specific aetiology. One patient with Crohn's and those with TB did not have any associated symptoms to suggest the diagnosis. Routine histopathological analysis in patients presenting with fistula inano should be performed as clinical prediction based on the nature of fistula may not be always accurate.

\section{Introduction}

Fistula-in-ano is a benign anal condition which has been described in literature for over 2500 years [1]. It is commonly encountered in colorectal surgical practice with a reported incidence of 8.6 per 100000 population [2]. The majority are simple fistulae which can be delineated fairly accurately and treated easily without significantly affecting the quality of life $[3,4]$. However, complex recurrent fistulae are challenging to treat and can have frequent recurrences requiring multiple surgeries [5]. Repeated surgical interventions can increase the risk of anal sphincter injury, which is often irreversible and can result in anal incontinence [6]. Some of these complex fistulae may have a specific cause which may be successfully managed medically such as tuberculosis (TB), Crohn's disease or actinomycosis. Diagnosis of these aetiological factors is aided by histopathological analyses. Studies that have analysed the histopathology of perianal fistula specimens to find a specific aetiology are few [7-10]. However, previous studies have not analysed the associated factors of specific aetiology in fistula-in-ano.

Therefore, this study was aimed to determine the yield of routine histopathology in identifying a specific aetiology in patients undergoing surgical treatment for fistula-in-ano. Furthermore, the associated factors were also determined.

\section{Materials And Methods}


A retrospective analysis of the histopathology reports of the patients who underwent surgery for fistulae-inano without a diagnosis for the fistulae, over a period of 6 years (from 2011-2016) at the Professorial Surgical Unit at the National Hospital of Sri Lanka was done. All examinations and investigations were carried out by a senior consultant colorectal surgeon. Data including demographic parameters, type of fistulae, number and type of procedures, complexity of the fistula were prospectively entered into a computerised database. Fistulae with multiple external openings, high transphincteric, suprasphincteric and extrasphincteric fistulae and/or with high blind extensions or horseshoe tracts and/or were anterior in a female patient were defined as complex fistulae $[11,12]$. The anatomy and complexity of the fistulae were assessed by endoanal ultrasonography and examination under anaesthesia. During examination under anaesthesia, a segment or the entire tract of the fistulae were sent for histological evaluation to look for a specific aetiology.

Data were analysed using SPSS version 20. Data were expressed using odds ratio (OR), frequency and percentages where relevant. Pearson Chi square test was used to determine associations. Statistical significance was determined at an alpha of 0.05. Ethical clearance was obtained from Ethics Review Committee of National Hospital of Sri Lanka.

\section{Results}

A total of 215 patients underwent surgical treatment for fistula-in-ano during the study period. Histopathological analyses were carried out for all fistulae. The median age of the participants was 40 years (range, $14-73)$. Of the participants $82.8 \%(n=178)$ were males and $17.2 \%(n=37)$ were females. Around $75 \%(n=161)$ were simple fistulae and 25\% ( $n=54)$ were complex fistulae. The majority were recurrent fistulae $(n=145,67.4 \%)$. Most were transphincteric fistulae $(60.5 \%, n=130)$ followed by intersphincteric fistulae $(23.7 \%, n=51)$. Other types were superficial $(n=28,13 \%)$, suprasphincteric $(n=5,2.3 \%)$ and extrasphincteric fistulae $(n=1,0.5 \%)$.

The majority of the histopathological analyses showed only the presence of inflamed granulation tissue and did not reveal any evidence of a specific aetiology $(n=204,94.9 \%)$.

Two (0.9\%) patients had inflamed granulation tissue containing a non-caseating granulomata on histology. Further analysis with stains for acid fast bacilli were negative and no conclusive evidence of Crohn's disease was seen. Five (2.3\%) patients had conclusive changes of Crohn's disease on histology. Three (1.4\%) had granulomatous changes and stains for acid fast bacilli was conclusive of TB. One patient $(0.5 \%)$ had evidence of adenocarcinoma with mucinous differentiation.

The associated factors of a specific aetiology has been summarised in table 1. All patients with a specific aetiology were males. A significantly higher proportion of those having a specific aetiology were complex fistulae (82\% vs.18\%, Odds ratio: 15 (95\% Confidence interval (Cl): $3.3-76), p<0.001)$. Furthermore, significantly higher proportion had associated abscess/collections ( $45.5 \%$ vs. $12 \%$, OR: 6.3 (95\% Cl: 1.8-22), $p=0.001)$. Although a higher proportion of fistulae with specific aetiology were transphincteric fistulae $(82 \%$ vs. $59 \%)$, the association was not statistically significant $(p=0.217)$. The proportion of recurrent fistulae and level of internal opening were comparable between the two groups (table 1). 
Four out of five (80\%) Crohn's disease patients presented with a complex fistula of which, two were nonrecurrent. The remaining patient presented with a simple fistula which was non-recurrent and did not have any associated symptoms to suggest Crohn's disease. Three out of four patients with complex fistulae had altered bowel habits and abdominal pain at the time of presentation. However, the remaining patient with complex fistula had no other symptoms except for perianal discharge. Transphincteric fistulae were seen in 4 patients and one had an intersphincteric fistula. The internal opening was found below the dentate line in 4 patients and above the dentate line in 1 patient.

The two patients who were found to have a non-caseating granuloma had complex transphincteric fistulae with internal openings at the level of the dentate line with associated abscesses. All patients $(n=3)$ with TB had evidence of caseation in the granulomas and were positive for acid fast bacilli. All presented with recurrent fistulae and of them, two patients had an associated abscess. However, they did not have other systemic symptoms of TB. Two were transphincteric fistulae with internal opening below and at the level of the dentate line while one patient had a suprasphincteric fistula with the internal opening in the rectum.

The patient who was diagnosed to have a malignancy was a 57-year-old male who presented with a long standing transphincteric complex fistula with multiple tracts with the internal opening at the level of dentate line. Furthermore, there was an induration in association with the fistula on rectal examination. Further investigation with imaging and endoscopy revealed that the adenocarcinoma developed in the longstanding fistula tract itself and was not part of a bowel malignancy.

\section{Discussion}

In this retrospective analysis of 215 patients who underwent evaluation for fistula-in-ano, eleven patients (5\%) had histopathological evidence of a specific aetiology. Complex fistula and presence of an abscess/ collection were found to be associated with a specific aetiology. Other factors such as type of fistula, level of internal opening, recurrence and presence of haemorrhoids were not associated with the diagnosis of a specific aetiology.

Fistula-in-ano is a common cause of perineal sepsis which can be very challenging to treat. Management of fistula-in-ano is complex and includes control of infection, assessment of the anatomy of the fistula tract by examination under anaesthesia and imaging followed by the definitive treatment [13]. Most fistulae-in-ano are idiopathic or cryptoglandular in origin which are usually simple, uncomplicated and respond well to treatment. Surgical treatment is the treatment of choice for idiopathic fistulae. However, surgery carries a risk of injury to the anal sphincter complex and can result in complications such as anal incontinence which can be extremely disturbing to the patient $[14,15]$.

However, fistulae occurring secondary to a specific causes is known to occur infrequently, which can be managed pharmacologically. These usually present as recurrent, complex fistulae-in-ano which are often difficult to manage. Some of the known specific causes are tuberculosis, Crohn's disease, actinomycosis, chlamydia and malignancies which can present as recurrent fistulae-in-ano [16]. The incidence of TB and acquired immunodeficiency syndrome (AIDS) are on the rise especially in developing countries [17]. 
Therefore, excluding the possible specific cause is necessary in order to decide on the definitive treatment.

Previous studies that have analysed the histopathological findings have been summarised in Table 2 [7-10].

Table 1

Associated factors of specific aetiology in anal fistulae

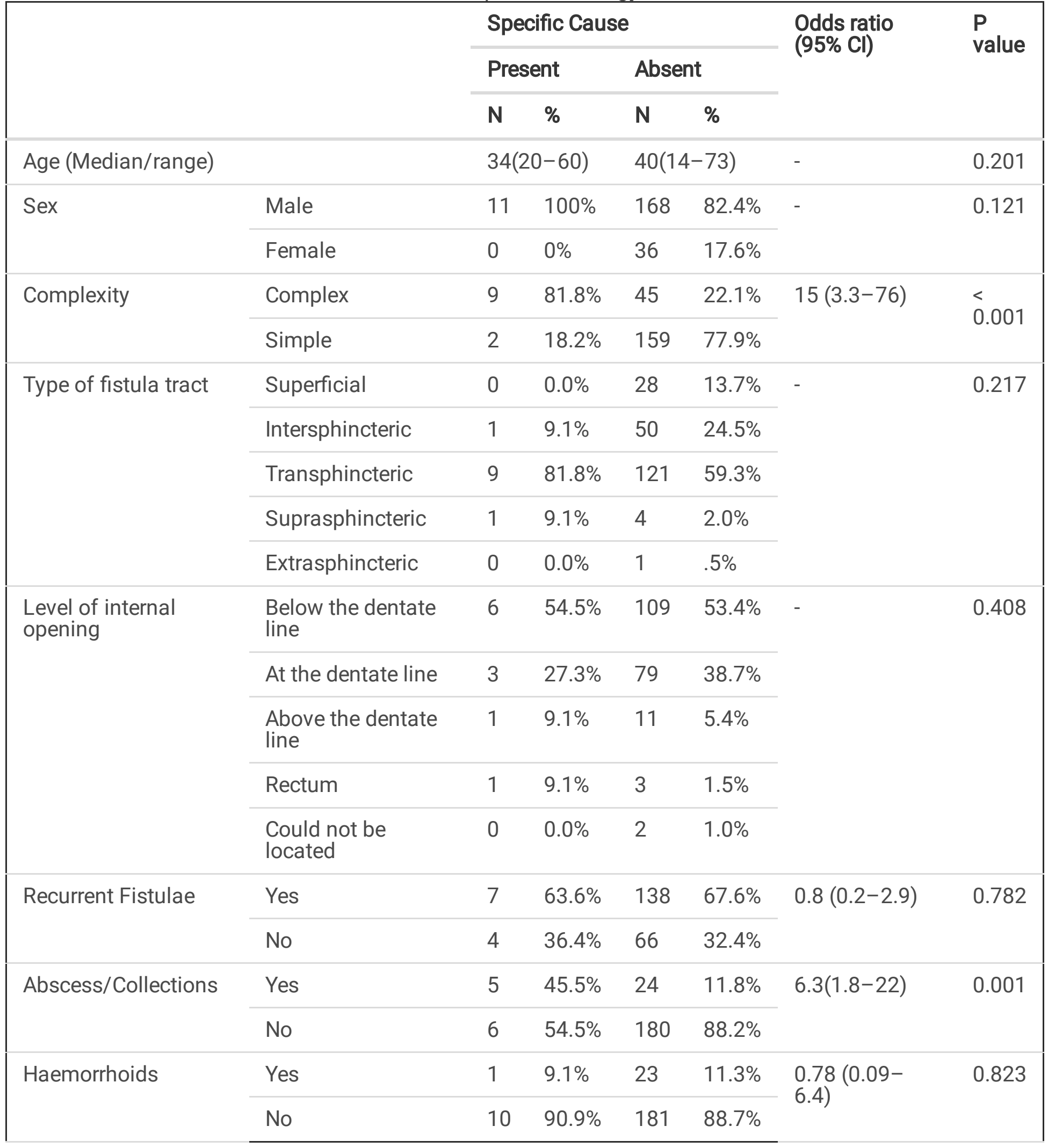


In a study from Sri Lanka involving 84 patients, TB was confirmed in two (2.4\%) patients. Both patients were suspected to have a specific causes clinically as they presented with recurrent fistulae with poor response to the surgical treatment [10]. In a prospective study of 96 patients from South Africa, 7 (7.3\%) were found to have tuberculosis. Of those, none had systemic manifestations of TB and only one had some evidence of TB in the chest radiograph. [9]. Sainio et al conducted a study in Helsinki and noted that $0.2 \%$ of all fistulae are tuberculous in origin [8]. However, in that population based study, those with previous history of TB were not excluded from the analysis. In a study by Shukla et al from India, 122 cases of fistulae in-ano were analysed and a considerable proportion (15.6\%) were diagnosed as tuberculosis [7]. Anorectal TB is usually associated with pulmonary TB but the occurrence of anorectal TB without pulmonary involvement in also reported in literature $[18,19]$. In our study 3 patients $(1.4 \%)$ were found to have anorectal TB. Of which 2 were complex fistulae and all three were recurrent fistulae. Furthermore, they did not have any other systemic features of TB and thus histology was useful to clinch the diagnosis.

\section{Prevalence of Crohn's disease in fistula-in-ano}

Anorectal fistula is a known manifestation of Crohn's disease and it usually occurs with other classical symptoms of Crohn's disease. The presentation of perianal Crohn's disease is variable as some (5\%) may even develop anal fistulae prior to other manifestations of Crohn's disease [19-21]. Although Crohn's disease was previously regarded as a disease of the Western world, it is increasingly being reported in South Asia [22]. In a study by Sainio et al involving 458 patients with anal fistulae, 1.3\% were secondary to Crohn's disease [8]. Interestingly, a higher proportion (1.5\%) were associated with ulcerative colitis. In our study, there was no anal fistulae associated with ulcerative colitis, although an increasing incidence of ulcerative colitis is noted in the South Asian region [23]. However, the study conducted by Sainio et al was a population based study, therefore it is possible that those with previous confirmed ulcerative colitis were also included in the analysis [8]. In a similar study from Sri Lanka including 84 patients, one patient (1.2\%) was diagnosed of Crohn's disease [10]. In the present study, 5 patients (2.3\%) were found to have Crohn's disease of which, four patients $(80 \%)$ presented with a complex fistulae. However, the remaining patient presented with a nonrecurrent simple fistula without any associated symptoms to suspect the diagnosis Crohn's disease. This finding is clinically significant as it is evident that non-recurrent simple fistulae can also have a specific aetiology. Interestingly, two out of five patients did not have any other associated symptoms to suggest a possibility of Crohn's disease at the time of presentation. However, they later manifested other symptoms of Crohn's disease. Therefore, histological evaluation in these patients was helpful to diagnose Crohn's disease early.

Malignancy associated with a recurrent anal fistula is a rare entity and it is reported to occur in long standing fistulae [24]. In our study, one patient was found to have adenocarcinoma with mucinous differentiation. The patient was a 57-year-old male with a history of long standing fistula for four years. There was an induration in association with the fistula on rectal examination and thus, the history was suggestive. Other studies summarised in table 1 did not find an associated malignant histological finding.

Although a few studies have analysed the histological findings in fistula-in-ano (Table 2), the associated factors of fistulae with a specific aetiology was not previously studied. In this study, we have shown that in 
few patients, histology was useful in detecting the specific aetiology in the absence of clinical features. This was not reported in previous studies.

Table 2: Summary of previous studies comparing histological findings of anal fistula

\begin{tabular}{|lllllllll|}
\hline Author & Year & Country & Sample & Study type & TB & Crohn's & Malignancy & Others \\
\hline Sainio & 1983 & Finland & 458 & $\begin{array}{l}\text { Population } \\
\text { based study }\end{array}$ & $\begin{array}{l}1 \\
(0.2 \%)\end{array}$ & $\begin{array}{l}6 \\
(1.30 \%)\end{array}$ & None & $\begin{array}{l}\text { UC: } \\
7(1.5 \%)\end{array}$ \\
\hline Shukla & 1988 & India & 122 & Retrospective & $\begin{array}{l}19 \\
(15.6 \%)\end{array}$ & None & None & None \\
\hline Stupart & 2009 & $\begin{array}{l}\text { South } \\
\text { Africa }\end{array}$ & 96 & Prospective & $\begin{array}{l}7 \\
(7.3 \%)\end{array}$ & None & None & None \\
\hline Wijekoon & 2010 & $\begin{array}{l}\text { Sri } \\
\text { Lanka }\end{array}$ & 84 & Retrospective & $\begin{array}{l}2 \\
(2.4 \%)\end{array}$ & $\begin{array}{l}1 \\
(1.2 \%)\end{array}$ & None & None \\
\hline Present study & $\begin{array}{l}\text { Sri } \\
\text { Lanka }\end{array}$ & 215 & Retrospective & $\begin{array}{l}3 \\
(1.4 \%)\end{array}$ & $\begin{array}{l}5 \\
(2.3 \%)\end{array}$ & $1(0.5 \%)$ & $\begin{array}{l}\text { NCG: } \\
(0.9 \%)\end{array}$ \\
\hline
\end{tabular}

\section{Conclusion}

In our study, the prevalence of Crohn's disease, TB and malignancy were 2.3\% $(n=5), 1.4 \%(n=3)$ and $0.5 \%$ $(n=1)$ respectively. Complex fistula and the presence of an abscess/ collection were the only associated factors of a specific aetiology. Other factors such as type of fistula, level of internal opening, recurrence and presence of haemorrhoids were not associated with a specific aetiology. Routine histopathological analysis in patients presenting with fistula in-ano may be useful to detect any specific aetiology early which will be helpful in the management of these patients.

\section{Limitations}

Being a retrospective analysis is a limitation. However, we found that in certain cases it was difficult to predict those with a possible underlying disease clinically. Thus, routine histopathological analysis was useful to detect specific aetiology early. However, the usefulness and cost-effectiveness can only be confirmed by large prospective studies.

\section{Abbreviations}

TB

Tuberculosis

SPSS

Statistical package for social sciences

AIDS 
Acquired immunodeficiency syndrome

OR

Odds ratio

$\mathrm{Cl}$

Confidence interval

\section{Declarations}

Ethics approval and consent to participate: Ethical approval was obtained from the Ethics Review Committee of the National Hospital of Sri Lanka. Consent is not aplicable as it was a retrospective analysis.

Consent for publication: Not applicable

Availability of data and materials: The datasets generated and analysed during the current study are available from the corresponding author on reasonable request.

Competing interests: The authors declare that they have no competing interests.

Funding: None.

Authors' contributions: UJ, ISA and DNS conceptualized the study. ISA, and UJ collected and analyzed the data. All authors were involved in drafting the manuscript. All authors read and approved the final manuscript.

Acknowledgements: None.

\section{References}

1. Nelson RL, Abcarian H. (2014) Epidemiology, incidence and prevalence of fistula in ano. In: Anal Fistula. Springer, pp 1-3.

2. Nelson R. Anorectal abscess fistula: what do we know? Surg Clin North Am. 2002;82(6):1139-51.

3. Jayarajah U, Wickramasinghe DP, Samarasekera DN. Anal incontinence and quality of life following operative treatment of simple cryptoglandular fistula-in-ano: a prospective study. BMC Res Notes. 2017;10(1):572.

4. Jayarajah U, Samarasekera DN. Predictive accuracy of Goodsall's rule for fistula-in-ano. Ceylon Med J. 2017;62(2):97-9. doi:10.4038/cmj.v62i2.8474.

5. Bubbers EJ, Cologne KG. Management of complex anal fistulas. Clin Colon Rectal Surg. 2016;29(1):43.

6. Malik A, Nelson R. Surgical management of anal fistulae: a systematic review. Colorectal Dis. 2008;10(5):420-30.

7. Shukla H, Gupta S, Singh G, Singh P. Tubercular fistula in ano. Br J Surg. 1988;75(1):38-9.

8. Sainio P. Fistula-in-ano in a defined population. Incidence and epidemiological aspects. In: Annales chirurgiae et gynaecologiae, 1983. vol 4. pp 219-224. 
9. Stupart D, Goldberg P, Levy A, Govender D. Tuberculous anal fistulas-prevalence and clinical features in an endemic area. S Afr J Surg. 2009;47(4):116-21.

10. Wijekoon N, Samarasekera D. The value of routine histopathological analysis in patients with fistula inano. Colorectal Dis. 2010;12(2):94-6.

11. Whiteford MH, Kilkenny J 3rd, Hyman N, Buie WD, Cohen J, Orsay C, Dunn G, Perry WB, Ellis CN, Rakinic J, Gregorcyk S, Shellito P, Nelson R, Tjandra JJ, Newstead G, Standards Practice Task F, American Society of C, Rectal S. Practice parameters for the treatment of perianal abscess and fistula-in-ano (revised). Dis Colon Rectum. 2005;48(7):1337-42. doi:10.1007/s10350-005-0055-3.

12. Parks AG, Gordon PH, Hardcastle JD. A classification of fistula-in-ano. Br J Surg. 1976;63(1):1-12.

13. Shawki S, Wexner SD. Idiopathic fistula-in-ano. World J Gastroenterol. 2011;17(28):3277-85.

14. Garcia-Aguilar J, Belmonte C, Wong WD, Goldberg SM, Madoff RD. Anal fistula surgery. Dis Colon Rectum. 1996;39(7):723-9.

15. Ozuner G, Hull TL, Cartmill J, Fazio VW. Long-term analysis of the use of transanal rectal advancement flaps for complicated anorectal/vaginal fistulas. Dis Colon Rectum. 1996;39(1):10-4.

16. Seow-Choen F, Nicholls R. Anal fistula. Br J Surg. 1992;79(3):197-205.

17. World Health Organization. Global tuberculosis report 2016 (2016).

18. O'Donohoe M, Waldron R, O'Malley E. Miliary tuberculosis presenting as an acute perianal abscess. Dis Colon Rectum. 1987;30(9):697-8.

19. Álvarez J, Gutiérrez V, Del Riego J, García I, Arizcun A, Vaquero C. Úlceras perianales de origen tuberculoso. Aportación de tres nuevos casos. Rev Esp Enferm Dig. 1992;81:46-8.

20. Lockhart-Mummery H. Crohn's disease: anal lesions. Dis Colon Rectum. 1975;18(3):200-2.

21. Hellers G, Bergstrand O, Ewerth S, Holmström B. Occurrence and outcome after primary treatment of anal fistulae in Crohn's disease. Gut. 1980;21(6):525-7.

22. Jayarajah U, Navarathne NM, de Zoysa IM, Subramaniam N, Samarasekera N, L Seneviratne S. Crohn's Disease in South Asia. International Journal of Progressive Sciences Technologies. 2017;6(1):12.

23. Jayarajah U, Navarathne NMM, Samarasekera N, Subramaniam N, de Zoysa IM, Seneviratne SL. Epidemiology, Pathogenesis and Treatment of Ulcerative Colitis in South Asia. International Journal of Progressive Sciences Technologies. 2017;6(1):8.

24. McAnally AK, Dockerty M. Carcinoma developing in chronic draining cutaneous sinuses and fistulas. Surg Gynecol Obstet. 1949;88(1):87-96. 